\title{
Influence of the Co(III) Porphyrinates Structure on the Electrochemical and Sorption Properties of the Ion-Selective Membranes Based on Them
}

\author{
A. B. Valiotti, G. I. Shumilova, and A. A. Starikova \\ St. Petersburg State University, Universitetskaya nab. 7-9, St. Petersburg, 199034 Russia \\ e-mail: AnnStarikova88@gmail.com
}

Received April 9, 2015

\begin{abstract}
The influence of the electronic and steric effects of the $p-\mathrm{OCH}_{3}, p-\mathrm{Cl}$, and $o-\mathrm{NHCOC}\left(\mathrm{CH}_{3}\right)_{3}$ substituents in the phenyl rings of $\mathrm{Co}$ (III) tetraphenylporphyrinates as well as that of the introduction of the axial nitrogen-containing ligand (dodecylimidazole) on the anionic selectivity of the membranes has been studied. It has been stated that the substitution at the phenyl cycles of the porphyrin had no significant influence on the anionic selectivity of the membrane, whereas the introduction of the axial nitrogen-containing ligand reduced the membrane specificity, the selectivity series approaching the classical Hofmeister series. All the studied electrodes have exhibited the enhanced (as compared to the Hofmeister series) selectivity towards nitrite, hydrocarbonate, and hydrophosphate anions.
\end{abstract}

Keywords: porphyrinate, cobalt, axial ligand, ion-selective electrode, selectivity, sorption

DOI: $10.1134 / \mathrm{S} 1070363215110237$

Development of ions-selective electrodes has been currently directed mainly on the detailed investigation of the selectivity and mechanism of the electrode reactions in order to extend the range of the practical application of ion-selective electrodes in the clinical practice and environmental studies.

Various anion-exchangers (salts of quaternary ammonium, phosphonium, and arsonium bases, triphenylmethane dyes, and phenanthroline metal complexes) serve as the membrane-active component of the anion-selective electrodes. The selectivity of membranes based on the quaternary ammonium salts is determined by the solvation energy of the corresponding anions, the latter being arranged in the Hofmeister series according to this parameter [1]: $\mathrm{ClO}_{4}^{-}>\mathrm{SCN}^{-}>\mathrm{I}^{-}>\mathrm{NO}_{3}^{-}>\mathrm{Br}^{-}>\mathrm{NO}_{2}^{-}>\mathrm{Cl}^{-}>\mathrm{HCO}_{3}^{-}>$ $\mathrm{SO}_{4}^{2-}>\mathrm{HPO}_{4}^{2-}$.

The selectivity with respect to anions can be altered as compared to the Hofmeister series in the case of the selective interactions of the active membrane components with dissolved anions. Examples of such selectivity modifiers include certain lipophilic derivatives of $B_{12}$ vitamin and the structurally similar metal porphyrinates [2-6], the latter being of undoubtful interest for development of ion-selective membranes [7-10].

Upon formation of metal complexes with synthetic porphyrins, the metal ion is inserted in the cavity of the macrocyclic ligand and is strongly bound to the donor atoms of the latter. The porphyrinates properties are largely determined by the incorporation of the metal ion into the conjugated electronic system of the macrocycle and the possibility of interaction with additional axial ligands.

In this work we pioneered in study of the membranes containing the electrode-active thiocyanate salts of Co(III) porphyrinates. For the sake of comparison, we included the complex 1 based on mesotetraphenylporphin into consideration (The Hammett constant of the substituents in the phenyl ring $\sigma_{\mathrm{H}} \equiv 0$ ); the effect of the substitution at the phenyl groups were studied using the complexes of meso-tetra( $p$-methoxyphenyl)porphin $2\left(\sigma_{p \text {-OMe }}-0.25\right)$, meso-tetra( $p$-chlorophenyl)porphin $3\left(\sigma_{p-\mathrm{Cl}} 0.23\right)$, and meso-tetra(o-pivalamidophenyl)porphin 4. Compounds 5 and $\mathbf{6}$ were similar to the complexes $\mathbf{2}$ and 4, respectively, but 
Scheme 1.

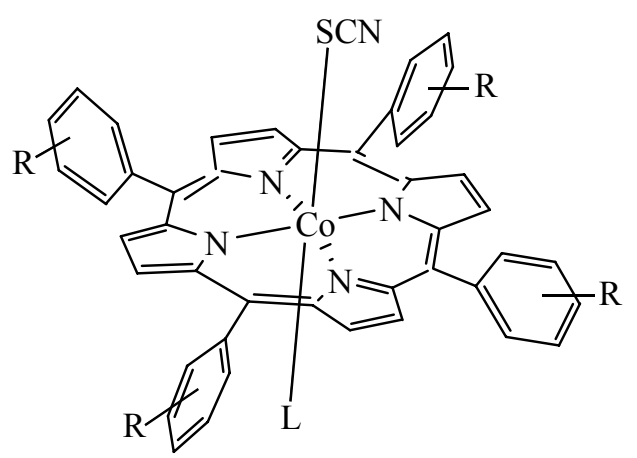

$\mathrm{R}=\mathrm{H}(\mathbf{1}), n-\mathrm{OCH}_{3}(\mathbf{2}, \mathbf{5}), n-\mathrm{Cl}(\mathbf{3}), o-\mathrm{NHCOC}\left(\mathrm{CH}_{3}\right)_{3}(\mathbf{4}$, 6); $\mathrm{L}=\mathrm{H}_{2} \mathrm{O}(\mathbf{1 - 4}), N$-dodecylimidazole $(\mathbf{5}, \mathbf{6})$.

additionally contained the axial ligand, $N$-dodecylimidazole, instead of water.

Hence, the study of anionic selectivity of the membranes containing the modified porphyrinates 1-6 should allow elucidation of different effects: the electronic effect of the donor $\left(p-\mathrm{OCH}_{3}\right)$ and acceptor ( $p-\mathrm{Cl}$ ) substituent (compounds 2 and $\mathbf{3}$ ), the steric effect of the bulky pivalamide group (compound $\mathbf{4}$ and 6), and the effect of the axial nitrogen-containing ligand (compounds 5 and 6) (Scheme 1).

It could be expected that the introduction of the donor group (compound 2) would reduce the charge at the cobalt atom and facilitate elimination of the thiocyanate anion. On the contrary, the acceptor substituent (compound 3) was supposed to increase the charge at the cobalt atom, promoting the specific

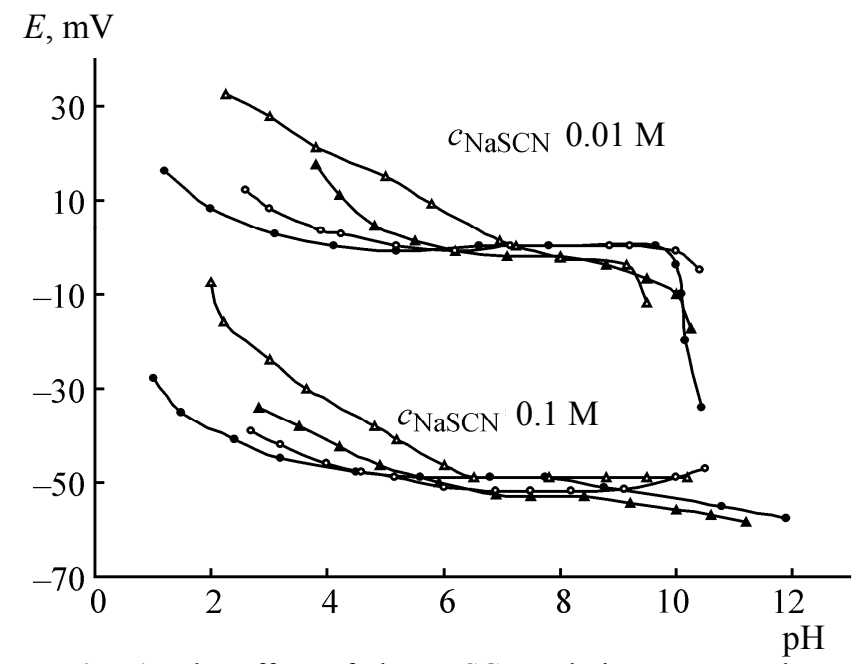

Fig. 1. The effect of the $\mathrm{NaSCN}$ solutions $\mathrm{pH}$ on the potential of the electrodes based on $\mathrm{Co}(\mathrm{III})$ porphyrinates.

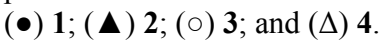

interaction of the porphyrin with anions and leading to deviation of the selectivity from the Hofmeister series. The bulky substituent in the phenyl fragment (compound 4) should decrease the donor properties of the phenylene fragment via moving it out the porphyrin cycle plane; on top of that, the used substituent contained the peptide fragment capable of hydrogen bonding. Finally, the expected effect of introduction the neutral nitrogen-containing ligand (compounds $\mathbf{5}$ and 6) was similar to that of the $p-\mathrm{OCH}_{3}$ substituent: decrease of the charge at the cobalt atom and weakening of its bond with thiocyanate anion.

The following properties were probed for the potentially thiocyanate-sensitive membranes based on the studied porphyrinates: electrical resistance, dependence of the membrane potential on the $\mathrm{pH}$ of the analyzed solution and the thiocyanate anions concentration, and the selectivity coefficient of the membranes with respect to extraneous anions.

The electrical resistance of the membranes was relatively high $(2-16 \mathrm{MOhm}$; the lowest value corresponded to the membrane based on porphyrinate $\mathbf{1}$, and those based of the modified porphyrinates exhibited the higher resistance). Nevertheless, we could reproducibly measure the emf values in the experiments using such membranes.

Metal porphyrinates readily bind hydroxyl ion as the axial ligand; that determines sensitivity of the electrochemical properties of the derived membranes to $\mathrm{pH}$ of the analyzed solution. Figure 1 displays the potential of the electrodes based on compounds 1-4 as function of $\mathrm{pH}$ of sodium thiocyanate solution.

The potential of electrodes based on all the studied complexes was independent on the medium acidity over certain $\mathrm{pH}$ range: $5.0-10.0$ (compounds $\mathbf{1}$ and 2) and 6.0-9.0 (compounds 3 and 4). The sensitivity of the measured potential to $\mathrm{pH}$ in the acidic medium was due to protonation of thiocyanate ions and decrease of the concentration of their ionic form in the membrane. As expected, the protonation effect was more prominent for the porphyrinates with the weakened binding of thiocyanate ion to cobalt ion (compounds 2 and 4). The change of the potential measured at alkaline $\mathrm{pH}$ values was due to the substitution of the axial ligand (thiocyanate ion) with hydroxyl ion. That was further confirmed by the fact that the sensitivity to $\mathrm{pH}$ was especially strong in the systems containing $0.01 \mathrm{~mol} / \mathrm{L}$ of $\mathrm{NaSCN}$, being less prominent when the $\mathrm{NaSCN}$ concentration was up to $0.1 \mathrm{~mol} / \mathrm{L}$. Let us note 


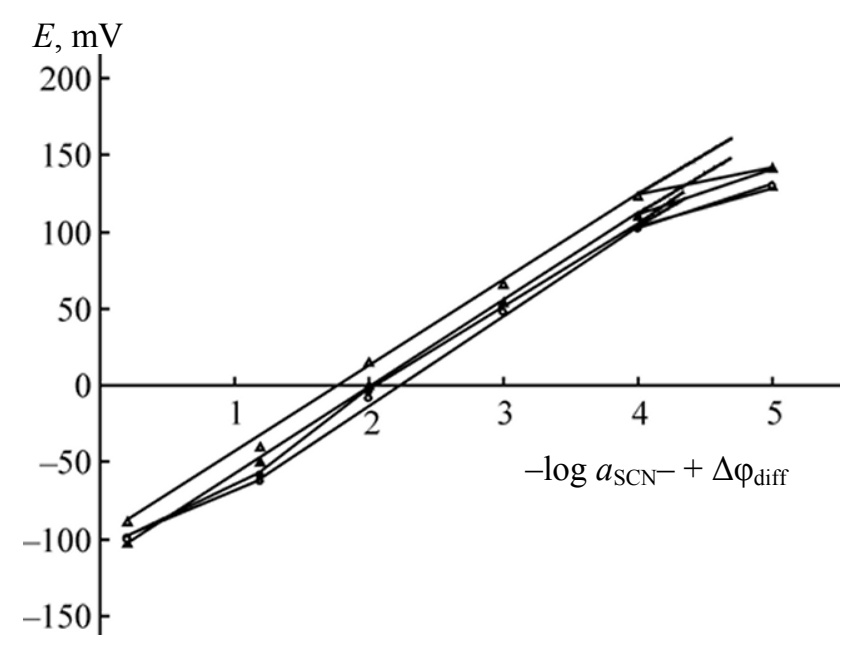

Fig. 2. The emf of galvanic element (1) with electrodes based on $\mathrm{Co}$ (III) porphyrinates as function of $-\log a_{\mathrm{SCN}}{ }^{-}+$ $\Delta \varphi_{\text {diff }}$ in the NaSCN solutions. $(\bullet) 1\left(\alpha_{\text {exp }}-55.0 \mathrm{mV} / \mathrm{dec}\right)$;

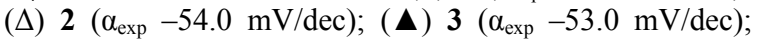
(०) $4\left(\alpha_{\exp }-55.0 \mathrm{mV} / \mathrm{dec}\right)$.

that the mentioned ligand exchange did not necessarily occur via the direct substation of the $\mathrm{SCN}^{-}$ligand with $\mathrm{OH}^{-}$ion. Instead, the basic hydroxyl ion could detach a proton off the coordinated $\mathrm{H}_{2} \mathrm{O}$ molecule (that was converted into the coordinated hydroxyl ion), thus facilitating the subsequent elimination of thiocyanate ion. Such process was favored by the presence of the $p$ - $\mathrm{Cl}$ acceptor (3). In the case of porphyrinate 4, deprotonation of the $\mathrm{NH}$ group was possible; that also reduced the charge at the central atom of the $\mathrm{Co}$ (III) porphyrinate and favored the thiocyanate ion elimination.

The response of an ion-selective electrode to the presence of the detected ion is known to be linear over the limited range of concentration of the latter. This range (i.e., the range of the concentration that can be determined) is the most important characteristic of the ion-selective electrode. Figure 2 shows the measured potential of the elements containing the membrane based on compounds 1-4 as function of the $-\log a_{\mathrm{SCN}}+$ $\Delta \varphi_{\text {diff }}$ value. All the electrodes exhibited the linear dependence of the potential on the logarithm of the detected anion concentration at $c_{\mathrm{NaSCN}}$ of $10^{-4}$ to $1.0 \mathrm{~mol} / \mathrm{L}$. The slope of the plots was approximately equal to $-55.0 \mathrm{mV} / \mathrm{dec}$; those values, somewhat underrated as compared to the theoretical one, were likely due to the contribution of $\mathrm{Na}^{+}$ions into the electricity transport in the membranes, thus reducing the transport number of thiocyanate ions to below unity.

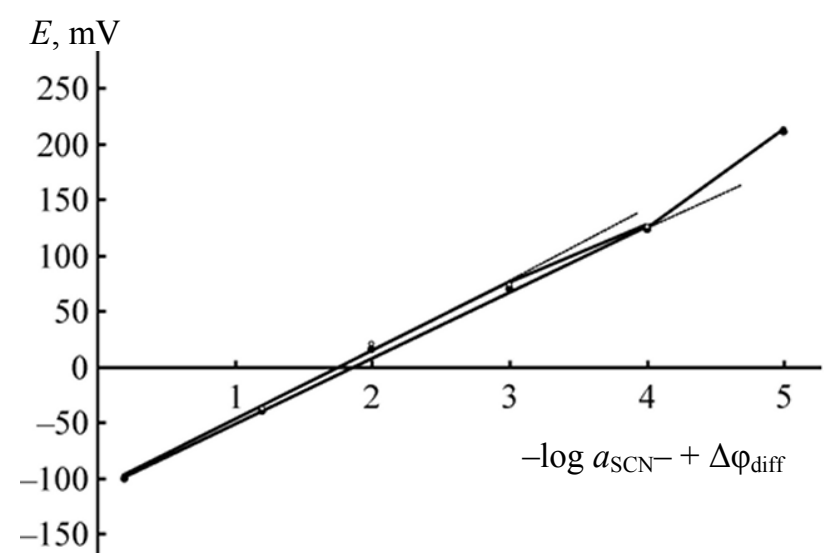

Fig. 3. The emf of the galvanic element (1) with the electrodes based on $\mathrm{Co}(\mathrm{III})$ porphyrinates 5 and $\mathbf{6}$ as function of $-\log a_{\mathrm{SCN}}{ }^{-}+\Delta \varphi_{\text {diff }}$ in the NaSCN solutions. (○) $5\left(\alpha_{\exp }-55.0 \mathrm{mV} / \mathrm{dec}\right)$; $(\bullet) 6\left(\alpha_{\exp }-55.0 \mathrm{mV} / \mathrm{dec}\right)$.

Figure 3 displays the $E=f\left(-\log a_{\mathrm{SCN}^{-}}+\Delta \varphi_{\text {diff }}\right)$ plots for the electrodes based on the Co(III) porphyrinates 5 and $\mathbf{6}$ containing the neutral nitrogencontaining ligand $\mathrm{N}$-dodecylimidazole.

In order to estimate the influence of the interfering ions by means of the biionic potentials method [13], i. e., sequential measurement of emf of the galvanic element in the solution containing the detected ion $\mathrm{X}^{-}$ (thiocyanate) and in the solution containing the interfering ion $\mathrm{Y}^{-}$, we determined the potentiometric selectivity coefficients $K_{\mathrm{X} / \mathrm{Y}}^{\mathrm{pot}}$ :

$$
\log K_{\mathrm{X} / \mathrm{Y}}^{\mathrm{pot}}=\frac{z_{\mathrm{x}}\left(E_{\mathrm{x}}-E_{\mathrm{y}}\right)}{\alpha} \cong \log \frac{a_{\mathrm{x}}}{a_{\mathrm{x}}^{\mathrm{x}_{\mathrm{x}} / z_{\mathrm{y}}}}+\Delta \varphi_{\text {diff, }},
$$

with $\alpha$, experimental value of the slope of the $E=$ $f\left(\log a_{\mathrm{X}}\right)$ curve.

Basing on the measured selectivity coefficients (see Table), we constructed the selectivity series of the studied thiocyanate-selective electrodes with respect to selected anions; those series differed from the classical Hofmeister extraction series of the quaternary ammonium bases:

$$
\begin{aligned}
& \mathrm{R}_{4} \mathrm{~N}^{+}: \mathrm{ClO}_{4}^{-}>>\mathrm{SCN}^{-}>>\mathrm{I}^{-}>>\mathrm{Br}^{-}>>\mathrm{NO}_{2}^{-}>>\mathrm{Cl}^{-} \\
& >>\mathrm{HCO}_{3}^{-}=\mathrm{SO}_{4}^{2-}>\mathrm{HPO}_{4}^{2-} \text {; } \\
& \text { compound 1: } \mathrm{SCN}^{-}>>\mathrm{I}^{-}>\mathrm{NO}_{2}^{-}>\mathrm{ClO}_{4}^{-}=\mathrm{HCO}_{3}^{-}>\mathrm{HPO}_{4}^{2-} \\
& >>\mathrm{Br}^{-}>\mathrm{Cl}^{-}>>\mathrm{SO}_{4}^{2-} \\
& \text { compound 2: } \mathrm{SCN}^{-}>>\mathrm{NO}_{2}^{-}>\mathrm{I}^{-}>\mathrm{ClO}_{4}^{-}>\mathrm{HPO}_{4}^{2-}>>\mathrm{Br}^{-}> \\
& \mathrm{Cl}^{-}>>\mathrm{SO}_{4}^{2-} \text {; }
\end{aligned}
$$


VALIOTTI et al.

Selectivity of the membranes based on porphyrinates 1-6 with respect to various anions

\begin{tabular}{c|c|c|c|c|c|c|c|c}
\hline \multirow{2}{*}{ Compound } & \multicolumn{7}{c}{$\log K_{\mathrm{SCN} / \mathrm{X}}^{\mathrm{pot}}$} \\
\cline { 2 - 9 } & $\mathrm{ClO}_{4}^{-}$ & $\mathrm{I}^{-}$ & $\mathrm{Br}^{-}$ & $\mathrm{NO}_{2}^{-}$ & $\mathrm{Cl}^{-}$ & $\mathrm{HCO}_{3}^{-}$ & $\mathrm{SO}_{4}^{2-}$ & $\mathrm{HPO}_{4}^{2-}$ \\
\hline $\mathrm{R}_{4} \mathrm{~N}^{+}$ & 0.79 & -0.62 & -2.28 & -3.00 & -3.80 & -4.80 & -4.80 & -5.00 \\
$\mathbf{1}$ & -2.00 & -1.20 & -3.22 & -1.40 & -3.50 & -2.00 & -4.40 & -2.40 \\
$\mathbf{2}$ & -1.50 & -1.30 & -3.60 & -0.90 & -3.75 & -4.50 & -4.15 & -1.80 \\
$\mathbf{3}$ & -2.40 & -1.08 & -3.70 & -1.20 & -3.70 & -1.50 & -4.05 & -1.75 \\
$\mathbf{4}$ & -2.00 & -2.75 & -3.75 & -0.72 & -4.20 & - & - & - \\
$\mathbf{5}$ & 1.30 & -0.60 & -3.50 & -2.60 & -3.30 & -2.80 & -3.80 & -3.30 \\
$\mathbf{6}$ & 1.20 & -0.70 & -3.70 & -2.86 & -3.50 & -1.80 & -3.84 & -0.90 \\
\hline
\end{tabular}

compound 3: $\mathrm{SCN}^{-}>>\mathrm{I}^{-}>\mathrm{NO}_{2}^{-}>\mathrm{HCO}_{3}^{-}>\mathrm{HPO}_{4}^{2-}>\mathrm{ClO}_{4}^{-}$

$$
>>\mathrm{Br}^{-}=\mathrm{Cl}^{-}>\mathrm{SO}_{4}^{2-}
$$

compound 4: $\mathrm{SCN}^{-}>\mathrm{NO}_{2}^{-} \gg \mathrm{ClO}_{4}^{-}>>\mathrm{I}^{-}>\mathrm{Br}^{-}>>\mathrm{Cl}^{-}$.

As compared to the case of quaternary ammonium bases, the $\mathrm{ClO}_{4}^{-}$weakly affected the $\mathrm{SCN}$ function, whereas the influence of the basic ions $\left(\mathrm{NO}_{2}^{-}, \mathrm{HCO}_{3}^{-}\right.$, $\mathrm{HPO}_{4}^{2-}$ ) was enhanced owing to their ability to form additional covalent bonds.

In view of the experimentally revealed enhanced binding of nitrite ions with the studied membranes, it was of interest to test the $\mathrm{NO}_{2}^{-}$-selective electrodes based on the studied porphyrinates. However, they exhibited poor performance: the response time was of 5-10 min, the electrodes resistance was significantly increased after a week, and the electrode function was rapidly deteriorating.

We further determined the anion selectivity for the membranes based on the porphyrinates 5 and $\mathbf{6}$ containing the axial nitrogen-containing ligand (see table). The imidazole ligand acted as a strong $\sigma$-donor, and the membranes selectivity was close to that of the classical systems (cf. the series for the quaternary ammonium bases):

$$
\begin{aligned}
& \text { compound 5: } \mathrm{ClO}_{4}^{-}>>\mathrm{SCN}^{-}>\mathrm{I}^{-}>>\mathrm{NO}_{2}^{-}>\mathrm{HCO}_{3}^{-}>\mathrm{Cl}^{-} \\
& =\mathrm{HPO}_{4}^{2-}>\mathrm{Br}^{-}>\mathrm{SO}_{4}^{2-} \text {; } \\
& \text { compound 6: } \mathrm{ClO}_{4}^{-}>>\mathrm{SCN}^{-}>>\mathrm{I}^{-}>\mathrm{HPO}_{4}^{2-}>>\mathrm{HCO}_{3}^{-} \\
& >\mathrm{NO}_{2}^{-}>\mathrm{Cl}^{-}>\mathrm{Br}^{-}>\mathrm{SO}_{4}^{2-} \text {. }
\end{aligned}
$$

To summarize, introduction of the donor or acceptor substituents at the phenyl fragment of $\mathrm{Co}$ (III) porphyrinate did not significantly change the electrochemical properties of the membranes based on those complexes, whereas the introduction of the axial nitrogen-containing ligand reduced the specificity of the porphyrin interaction with the anions, and the selectivity series approached the classical Hofmeister series. All the tested electrodes, including those based on the complex containing the axial $N$-dodecylimidazole ligand, exhibited the enhanced selectivity towards nitrite, hydrocarbonate, and hydrophosphate anions, as compared to the quaternary ammonium bases. The biionic potential method could be applied to estimate the sorption selectivity of the porphyrin-type compounds.

\section{EXPERIMENTAL}

The used Co(III) porphyrinates were synthesized by A.S. Semeikin et al. (Ivanovo State Chemical-Technological University). The compounds purity was confirmed by TLC, and they were identified by means of spectrophotometry [12].

The membranes were prepared from polyvinyl chloride S-66 (the carboxylic groups content below 1 $\mathrm{wt} \%$ according to IR spectroscopy data), $o$-nitrophenyl octyl ether (Fluka) was used the plasticizer, and the porphyrinates 1-6 were used as electrode-active species. The mass ratio of the membrane components was of $24.75: 74.25: 1$ (PVC : plasticizer : porphyrynate). The membranes were prepared as described elsewhere [14].

Potentiometric measurements were performed using the element (1) incorporating the studied membranes.

$\mathrm{pH}$ of the studied solutions was maintained using TRIS (0.01 $\mathrm{mol} / \mathrm{L})$ buffer [tris(oxymethyl)aminomethane hydrochloride, $\left.\mathrm{C}_{4} \mathrm{H}_{11} \mathrm{O}_{3} \mathrm{~N} \cdot \mathrm{HCl}\right]$.

All the electrodes were tested in the solutions of $\mathrm{Na}_{n}^{+} \mathrm{X}^{n-}$ salts $\left(\mathrm{X}^{n-}=\mathrm{SCN}^{-}, \mathrm{I}^{-}, \mathrm{NO}_{2}, \mathrm{ClO}_{4}^{-}, \mathrm{HCO}_{3}^{-}\right.$, 
$\mathrm{HPO}_{4}^{2-}, \mathrm{Br}^{-}, \mathrm{Cl}^{-}$, or $\mathrm{SO}_{4}^{2-}$ ) at the concentration of $10^{-5}-$ $1.0 \mathrm{~mol} / \mathrm{L}$. The stock solutions $(0.1$ and $1.0 \mathrm{~mol} / \mathrm{L})$ were prepared by weighing, the other solutions were diluted by volume. The membranes resistivity was measured via the method of Eckfeldt and Perley $[15,16]$.

The influence of $\mathrm{pH}$ on the electrodes potential was studied using the galvanic element (2) via sequential variation of $\mathrm{pH}$ of the $\mathrm{NaSCN}$ solutions by addition of concentrated $\mathrm{NaOH}$ or $\mathrm{H}_{2} \mathrm{SO}_{4}$ solution. The $\mathrm{pH}$ value of the studied solutions was maintained with the TRIS buffer $(0.01 \mathrm{~mol} / \mathrm{L})$; that allowed its variation over the wide range (2.5-9.0). That experiment was performed at two concentrations of NaSCN, $10^{-2}$ and $10^{-1} \mathrm{~mol} / \mathrm{L}$.

\section{REFERENCES}

1. Hofmeister. F., Arch. Exp. Pathol. Pharmacol. 1888, vol. 24 , p. 247.

2. Buhlmann, P., Pretsch, E., and Bakker, E., Chem. Rev., 1998, vol. 98, no. 4, p. 1593. DOI: $10.1021 /$ cr970113+.

3. Huzer, M., Morf, W.E., Fluri, K., Seiler, K., Schulthess, P., and Simon, W., Helv. Chim. Acta, 1990, vol. 73, no. 5, p. 1481. DOI: 10.1002/hlca., 19900730528.

4. Palet, C., Munoz, M., Daunert, S., Bachas, L.G., and Valiente, M., Anal. Chem., 1993, vol. 65, no. 11, p. 1533. DOI: $10.1021 / \mathrm{ac00059a009.}$

5. Park, S.B., Matuszewski, W., Meyerhoff, M.E., Liu, Y.H., and Kadish, K.M., Electroanalysis, 1991, vol. 3, no. 9, p. 909. DOI: 10.1002/elan.1140030906.
6. Daunert, S., Wallace, S., Florido, A., and Bachas, L.G., Anal. Chem., 1991, vol. 63, no. 17, p. 1676. DOI: 10.1021/ac00017a005.

7. Rezaei, B., Meghdadi, S., and Nafisi, V., Sensors and Actuators, 2007, vol. 121, no. 2, p. 600. DOI: 10.1016/ j.snb.2006.04.093.

8. Gorski, L., Malinowska, E., Parzuchowski, P., Zhang, W., and Meyerhoff, M.E., Electroanalysis, 2003, vol. 15, nos. 15-16, p. 1229. DOI: 10.1002/elan.200302814.

9. Pietrzak, M., Meyerhoff, M.E., and Malinowska, E., Analyt. Chim. Acta, 2007, vol. 596, no. 2, p. 201. DOI: 10.1016/j.aca., 2007.06.016.

10. Chen, L.D., Zou, X.U., and Buhlmann, P., Anal. Chem., 2012, vol. 84, no. 21, p. 9192. DOI: 10.1021/ac301910c.

11. Valiiotti, A.B., Vasil'eva, O.E., Starikova, T.A., Shumilova, G.I., and Semeikin, A.S., Russ. J. Gen. Chem., 2011, vol. 81, no. 4, p. 762. DOI: 10.1134/ S1070363211040256.

12. Berezin, B.D., Koordinatsionnye soedineniya porfirinov $i$ ftalotsianinov (Coordination Compounds of Porphyrins and Phthalocyanines), Moscow: Nauka, 1978.

13. Stepanek, R., Krautler, B., Schulthess, P., Lindemann, B., Ammann, D., and Simon, W., Analyt. Chim. Acta, 1986, vol. 182, p. 83. DOI: 10.1016/S0003-2670(00)82439-3.

14. Li, X. and Harrison, D.J., Anal. Chem., 1991, vol. 63, no. 19 , p. 2168. DOI: $10.1021 / \mathrm{ac} 00019 \mathrm{a} 018$.

15. Bates, R.G., Determination of $p H$ Theory and Practice, New York: Wiley, 1972.

16. Eckfeldt, E.L. and Perley, G.A., J. Electrochem. Soc., 1951, vol. 98(2), p. 37. DOI: 10.1149/1.2778103. 